\title{
DE TÁNGER A GIBRALTAR: EL ESTRECHO EN LA PRAXIS COMERCIAL E IMPERIAL BRITÁNICA (1661-1776)
}

por

\section{JosÉ IGNACIO MARTÍNEZ RUIZ}

Universidad de Sevilla

RESUMEN: El Mediterráneo constituyó una de las zonas preferentes para Inglaterra a partir de mediados del siglo XVII. Sin embargo, diversas circunstancias bicieron imposible que Tánger, cedida por Portugal en 1661, se convirtiera en el eje de los asuntos ingleses en la zona. Algo muy distinto ocurrió con Gibraltar, arrebatado a España en 1704. Mas allá de la reivindicación territorial y de la política imperial británica, Gibraltar se convirtió en un enclave comercial de rango internacional en el transcurso del siglo XVIII, aprovechando para ello su situación geográfica, su condición de puerto franco y su integración en la economía británica.

PAlABRAS Clave: Imperio británico. Tánger. Gibraltar. Comercio internacional. Puertos francos. Contrabando. Siglo XVII. Siglo XVIII.

ABSTRACT: The Mediterranean was one of the key zones for England from the mid-seventeenth century on. However, a number of different circumstances made it impossible for Tangier, ceded by Portugal in 1661, to become the bub of English naval activity in Southern Europe. The case of Gibraltar, seized from Spain in 1704, was very different. Beyond Spanish territorial vindication and British imperial policy, Gibraltar became an international trading enclave in the course of the eighteenth century, taking advantage of its geographical situation, its status as a free port, and its integration into the British economy.

KEY WORDS: British Empire. Tangier. Gibraltar. International trade. Free ports. Smuggling. Seventeenth century. Eighteenth century. 
La conquista de Jamaica, arrebatada a España en 1655, y la obtención de Bombay y Tánger, cedidas por Portugal en 1661, constituyen un punto de inflexión en la historia del imperio británico, entidad que por entonces apenas comprendía otros territorios que los situados en las costas atlánticas de América del Norte y Barbados y un rosario de factorías a lo largo de las costas africana y asiática ${ }^{1}$.

Ahora bien, mientras que Jamaica y Bombay se convirtieron casi de inmediato en piezas esenciales del entramado imperial británico, la ocupación de Tánger defraudó completamente las expectativas que había generado. En efecto, Jamaica desempeñó desde finales del siglo XVII un papel fundamental en los intercambios de manufacturas inglesas por materias tintóreas y plata procedentes de las colonias españolas en América, hasta el punto de que tales intercambios llegaron a rivalizar en magnitud con los que se llevaban a cabo directamente entre Inglaterra y España. Por lo que se refiere a Bombay, cuya administración fue confiada a la Compañía Inglesa de las Indias Orientales en 1672, bastará mencionar que pocos años después de su incorporación a Inglaterra logró desplazar a Surat como eje de los asuntos mercantiles británicos en $A_{s i a^{2}}$. Tánger, por el contrario, terminó siendo abandonada a comienzos del año 1684, esto es, menos de veinticinco años después de su cesión por Portugal. A partir de entonces y hasta el año 1704, en que tuvo lugar la conquista de Gibraltar, Inglaterra careció de una base propia en el Estrecho, circunstancia que comprometió su afianzamiento como primera potencia mercantil y marítima en la región.

El propósito de este artículo es doble: por una parte, analizar los factores que impidieron que Tánger se convirtiera en la piedra angular de los asuntos ingleses en el Mediterráneo; y, por otra, ofrecer una aproximación a la funcionalidad económica de Gibraltar en sus primeras décadas de existencia como plaza británica. Se trata de dos cuestiones claramente relacionadas pues el abandono de Tánger conllevó la búsqueda de una alternativa que garantizara la presencia efectiva de la flota británica en el Mediterráneo y la seguridad de los intercambios comerciales con Italia y Turquía —en junio de 1693 la flota que volvía de Turquía fue destruida cerca del Estrecho por barcos franceses, circunstancia que puso de manifiesto la fragilidad de dicha presencia- y esa alternativa fue Gibraltar. Los contemporáneos fueron conscientes de que la

\footnotetext{
1 En palabras de J.I. ISRAEL, «these developments fundamentally altered European perceptions of England's overseas Empire» («The Emerging Empire: The Continental Perspective, 16501713» en CANNY, N. ed.: The Origins of Empire. British Overseas Enterprise to the Close of the Seventeenth Century, The Oxford History of the British Empire, vol. I, Oxford, 1998, pág. 422).

2 Sobre la funcionalidad económica y la forma en que fueron administradas Jamaica y Bombay en el último tercio del siglo XVII véanse los estudios de ZAHEDIEH, N., "The Merchants of Port Royal, Jamaica, and the Spanish Contraband Trade, 1655-1692», en William and Mary Quarterly, 3rd. Series, vol. XLIII (1986), págs. 570-593 y MALONI, R., «Surat to Bombay: transfer of comercial power", en Itinerario. European Journal of Overseas History, 26: 1 (2002), págs. 61-74, respectivamente.
}

Hispania, LXV/3, núm. 221 (2005) 1043-1062 
conquista de la roca suponía retomar el camino iniciado con la posesión de Tánger, de ahí que Daniel Defoe, sin lugar a dudas uno de los más agudos observadores de la época, no dudara en contraponer el fracaso de la presencia inglesa en Tánger y la necesidad de que el Reino Unido consolidara la posesión de Gibraltar ${ }^{3}$.

Hasta el presente, de la historia de Gibraltar en el siglo XVIII apenas ha interesado otra cuestión que la de la reivindicación territorial, vistas las cosas desde el lado de España, o que la de su defensa como parte del imperio, vistas las cosas desde el lado británico. Con ser importantes las consideraciones de tipo diplomático o militar, la historia del Gibraltar inglés en el Setecientos debe explicarse desde una perspectiva más amplia. En efecto, mucho antes de que la roca se convirtiera en el siglo XIX en una pesadilla para los responsables de las aduanas españolas, la economía de Gibraltar generó unas actividades y creó una red de intereses que condicionaron el futuro de la plaza como parte del imperio británico e influyeron, modificándola, en la forma en que se planteaba la reivindicación territorial por parte de España.

\section{MITOS Y REALIDADES DEL TÁNGER INGLÉS (1661-1684)}

El proceso que llevaría a Inglaterra a convertirse en una de las potencias navales hegemónicas del Mediterráneo a partir del siglo XVII se inició en la década de 1570. Fue entonces cuando el colapso de Amberes como consecuencia de la sublevación de los Países Bajos y la guerra entre Venecia y Turquía (1570-73) crearon la necesidad y ofrecieron la oportunidad de prescindir de intermediarios y de acceder directamente a los centros productores de seda, especias y otras mercancías de valor como las pasas o el aceite de la zona mediterránea ${ }^{4}$. La culminación institucional de este proceso fue la creación de la Compañía de Turquía en 1580-81, de la Compañía de Venecia en 1583 y, como resultado de la fusión de las dos anteriores, de la Compañía de Levante en $1592^{5}$.

El principal bastión de Inglaterra en el Mediterráneo a mediados del siglo XVII era Livorno donde, al amparo de una legislación fiscal y mercantil extraordinariamente favorable, se habían establecido mercaderes de todas las nacionalidades. La presencia inglesa en la zona era tanto más importante por cuanto una parte significativa del comercio intramediterráneo se llevaba a cabo en barcos de dicho pabellón.

\footnotetext{
3 DEFOE, D.: A letter to the Independent Whig, occasioned by bis considerations of the importance of Gibraltar to the British Empire, London, 1720, págs. 18-23.

4 R. Davis, "England and the Mediterranean, 1570-1670", en F.J. Fisher, ed., Essays in the economic and social bistory of Tudor and Stuart England, Cambridge, 1961, págs. 117-137.

5 R. Brenner, Merchants and Revolution. Comercial Change, Political Conflict, and London's Overseas Traders, 1550-1653, 1993, págs. 17-18.
} 
En 1661 la ciudad y puerto de Tánger no era más que un enclave bien situado, por su cercanía al estrecho de Gibraltar, lo que no era poco sin duda, pero mal acondicionado desde un punto de vista militar y comercial 6 . A pesar de ello, Inglaterra apostó desde un primer momento por las posibilidades que ofrecía la plaza norteafricana en ambos aspectos, de ahí que, antes incluso de que se formalizara el matrimonio entre Carlos II de Inglaterra y la princesa portuguesa Catalina de Braganza, en virtud del cual tuvo lugar la cesión de Tánger a Inglaterra, se iniciaran las gestiones oportunas para fortificar la ciudad y construir un puerto digno de tal nombre y de ahí también que Tánger recibiera el estatuto de puerto franco en noviembre de $1662^{7}$.

La declaración de puerto franco significaba, básicamente, dos cosas: primero, que cualquier comerciante, independientemente de su nacionalidad, podría instalarse en Tánger sin temor a sufrir un trato discriminatorio y, segundo, que las mercancías que se descargaran en la ciudad no pagarían más que unos impuestos mínimos, equivalentes al $0.25 \%$ de su valor, pudiendo ser reexportadas de manera enteramente libre. El único límite fijado a condiciones tan generosas afectaba a los barcos que procedieran de más allá del cabo de Buena Esperanza o de cualquiera de las plantaciones británicas de América; en definitiva, que procedieran de las Indias Orientales u Occidentales. Pues bien, a pesar de medidas tan favorables, la ciudad no llegó a convertirse jamás en el «almacén general de mercancías» del que hablan los textos de la época ni en el centro de los asuntos ingleses en el Mediterráneo por lo que, como señalamos con anterioridad, terminó siendo evacuada a comienzos del año 1684. ¿A qué se debió esta decisión?

De entrada, podemos descartar que la falta de apoyo por parte de la Corona fuera la causa ya que, junto al estatuto de puerto franco, la plaza norteafricana fue favorecida también con la creación de un tribunal mercantil, jurisdicción que no existía ni siquiera en Londres donde los pleitos entre mercaderes se sustanciaban ante la justicia ordinaria ${ }^{8}$. Así mismo, con objeto favorecer la transferencia de capitales hacia la ciudad y, en definitiva, la negociación, se decidió que cada chelín tendría en Tánger 16 peniques en lugar de 12 y que el

6 La principal obra de referencia sobre el periodo inglés de la historia de Tánger sigue siendo el libro de RouTH, E.M.G.: Tangier: England's lost Atlantic outpost 1661-1684, London, 1912. Por lo que se refiere a los investigadores españoles, se han ocupado de Tánger SÁNCHEZ BELÉN, J.A., «La presencia inglesa en el Estrecho a fines del siglo XVII», en Actas del Congreso Internacional "El Estrecho de Gibraltar», tomo III, Madrid, 1988, págs. 29-44 y VALlADARES, R., «Inglaterra, Tánger y el 'Estrecho compartido'. Los inicios del asentamiento inglés en el Mediterráneo Occidental durante la guerra hispano-portuguesa (1641-1661)», en Hispania, LI/3, nº 179, 1991, págs. 965-991.

7 By the King. A Proclamation Declaring His Majesties pleasure to Settle and Establish a Free Port at His City of Tánger in Africa (16-11-1662).

8 La documentación generada por el tribunal se encuentra en el Public Record Office (PRO), CO 279, Board of Trade. Tangier, $\mathrm{n}^{\circ} 41$ (Proceedings of the Court Merchant, 1668-1679), $\mathrm{n}^{\circ} 42$ (Minute Book of the Court Merchant, 1676-1677), $n^{\circ} 43$ (Orders of the Court Merchant, 16791683) $\mathrm{y}^{\circ} 44$ (Proceedings of the Court Merchant, 1679-1683).

Hispania, LXV/3, núm. 221 (2005) 1043-1062 
tipo de cambio del real de a ocho de Castilla con respecto a la moneda inglesa sería de 6 chelines en lugar de 4.5. De esta manera, quienes llevaban su dinero a Tánger obtenían, de entrada, una ganancia del $33.3 \%$.

¿Qué ocurrió entonces? Sin que esto suponga prelación alguna, lo primero que debemos señalar es que las instalaciones portuarias del Tánger inglés progresaron con gran dificultad, consumieron una extraordinaria cantidad de recursos y nunca pudieron albergar barcos de gran tonelaje ${ }^{10}$. Los contemporáneos manejaron cifras fabulosas, asegurando haber visto «muchas vezes ciento y doscientos navíos juntos» en el puerto de Tánge ${ }^{11}$. Nada de eso. Los datos disponibles, procedentes del derecho de anclaje, permiten cuantificar el tráfico mercantil de Tánger en unos 150-160 barcos al año en su momento de mayor prosperidad, esto es, en la segunda mitad de la década de $1670^{12}$, así como constatar que a partir de entonces se inició un proceso de decadencia irreversible que redujo el tráfico portuario a poco más de 60 barcos al año a comienzos de la década de $1680^{13}$. La inmensa mayoría de estas embarcaciones, además, eran pequeños navíos del tipo barco longo, gabarra o tartana, circunstancia que, junto con otras informaciones a las que nos referiremos más adelante, confirman la idea de que Tánger no llegó a ser jamás un centro mercantil de rango internacional. Y no sólo por lo que acabamos de afirmar al respecto de sus instalaciones portuarias, sino también porque Tánger tenía que rivalizar con otros puertos francos del Mediterráneo occidental, ya muy consolidados en el último tercio del siglo XVII, como Livorno y Génova, o de reciente creación, como Marsella ${ }^{14}$.

9 De La Veronne, CH.: Tanger sous l'occupation anglaise d'après une description anonyme de 1674, París, 1972, pág. 89. El autor del manuscrito reconoce que «esta ganancia que parece avía de ser considerable, no es ninguna si se trata de sacar dineros de la plaça. (...). Porque si uno trae un real de a ocho a Tánger, le darán allí prontamente ocho shillingas por él, y si pide letra de esse real de a ocho para Inglaterra no le darán más que quatro y medio" (pág. 89).

10 En $A$ short account of the progress of the mole at Tangier from the first beginning of that work 1679 , se explican las dificultades de todo tipo que encontraron los trabajos de construcción del nuevo puerto entre 1662 y 1679, año en que la obra seguía pendiente de terminación.

11 De LA VeRONNE (1972), pág. 85.

12 Coincidiendo con la finalización de la tercera guerra anglo-holandesa y con una nueva proclamación real renovando las garantías ofrecidas a los mercaderes extranjeros de 13-1-1674.

13 Bodleian Library, Oxford. Rawl. Mss., D, 794. Estas cifras fueron parcialmente publicadas por Routh (1912), pág. 149.

14 Sobre Livorno, donde existía una importante colonia mercantil inglesa a mediados del siglo XVII, véanse los trabajos de HAYWARD, "The British Factory in Livorno", en Atti del Convegno 'Gli inglesi a Livorno e all'isola d'Elba, Livorno, 1980, págs. 261-267 y FILIPPINI, J.P., "Les Nations à Livourne (XVIIe-XVIIe siècles)", en CAVACIOCCHI, S. (a cura di), I porti come impresa economica, Firenze, 1988, págs. 581-594. Génova se convirtió en puerto franco el año 1590, aunque sólo para los productos alimenticios. Con posterioridad se produjo una liberalización progresiva de las transacciones que culminó el año 1654 (KIRK, T., «Genoa and Livorno: Sixteenth and Seventeenth-century Commercial Rivalry as a Stimulus to Policy Development», en History, 2001, págs. 3-17). Marsella fue declarada puerto franco por Colbert en marzo de 1669 (RAMBERT, G.: Histoire du commerce de Marseille, tome IV, París, 1954, pág. 207). 
Por si esto fuera poco, los cónsules y mercaderes ingleses establecidos en los puertos del sur de España se opusieron también al afianzamiento de Tánger como enclave comercial ${ }^{15}$. Los primeros, porque eran radicalmente contrarios a que las mercancías procedentes de Tánger entraran en España sin pagarles sus derechos de consulado ${ }^{16}$. Los mercaderes, sobre todo los de Cádiz, porque si se obligaba a los barcos ingleses que entraban o salían del Mediterráneo a ir a Tánger, como algunos pretendían, sus negocios podían verse afectados de manera muy negativa. El temor e inquietud de la colonia mercantil británica de Cádiz, la más importante de España, se entiende mejor si tenemos presente que la conquista de Jamaica, a partir de la cual se habían comenzado a distribuir las manufacturas inglesas en la América española sin necesidad de pasar por la península - en definitiva, sin la intermediación de los mercaderes británicos de Cádiz-, les había arrebatado buena parte de su actividad ${ }^{17}$. El afianzamiento de Tánger podía suponer, pues, un duro golpe para la colonia inglesa de Cádiz. En este sentido, no deja de llamar la atención que los principales beneficiarios de la condición de puerto franco de Tánger terminaran siendo los mercaderes franceses, cuya colonia de comerciantes llegó a ser, con diferencia, la más numerosa de la ciudad $^{18}$.

Tánger no llegó a desempeñar una función similar a la que tenían Livorno o Cádiz con respecto al comercio inglés en el Mediterráneo Occidental y en el Atlántico español, respectivamente. Pero, ise puede decir lo mismo por lo que se refiere a Berbería e, incluso, a las colonias británicas de América del Norte?

En la declaración de puerto franco del año 1662 se expresaba con toda rotundidad que uno de los objetivos de la medida era que Tánger sirviera de plataforma para las manufacturas inglesas en el norte de África, un territorio que por entonces no significaba más que el $2.7 \%$ del valor de las exportaciones y el

15 A discourse touching Tánger, 1680, págs. 38-40.

16 Téngase en cuenta, a este respecto, que el de cónsul era un cargo venal sin remuneración por parte del gobierno inglés. BARBOUR, V., "Consular service in the reign of Charles II', en American Historical Review, 33 (1928), págs. 553-78. Los mercaderes británicos de Cádiz mantuvieron por esta causa un duro enfrentamiento con el cónsul Martin Wescombe. En febrero de 1673 Wescombe trató de elevar los derechos que percibía, 150 reales de plata por barco, dando lugar a una fuerte oposición por parte de los mercaderes ingleses de la plaza. El contencioso tardó en zanjarse más de dos años y sólo se resolvió después de que una asamblea de mercaderes interesados en el comercio con España, celebrada en Londres por orden del Privy Council, rechazara la pretensión del cónsul (Calendar of State Papers, Domestic, Charles II, 372, 25 I y 25 II). Analizamos esta cuestión en J.I. Martínez Ruiz, «Making unregulated overseas trade work: English merchants in Spain in the Seventeenth Century» (Economic History Society, Annual Conference, Birmingham, abril 2002).

17 Algunos de los mercaderes ingleses que se instalaron en Port Royal, entre ellos Thomas Brailsford, habían tenido previamente intereses en el comercio americano a través de Cádiz. ZAHEDIEH (1986), pág. 579.

18 De La Veronne (1972), pág. 87. Según el autor del manuscrito, en Tánger se bebía más vino francés que español y abundaban más las ropas de Francia que de Inglaterra. 
$0.3 \%$ de las importaciones de Inglaterra ${ }^{19}$. Ahora bien, como las relaciones entre Inglaterra y las regencias del norte de África se caracterizaron en el último tercio del siglo XVII por la hostilidad antes que por la colaboración, a pesar de la firma de acuerdos en 1662, 1663, 1666 y 1670, las relaciones mercantiles de Inglaterra con Berbería continuaron siendo en estos años enormemente precarias. Incluso a la hora de abastecerse de productos perecederos Tánger dependía de las cercanas costas españolas antes que de los territorios norteafricanos circundantes ${ }^{20}$.

La referencia que hicimos con anterioridad a la existencia de relaciones mercantiles directas entre las colonias británicas de América del Norte y Tánger puede resultar, de entrada, sorprendente, pues el texto de la proclamación de puerto franco excluía de manera explícita tal posibilidad. Los intercambios, sin embargo, existieron ${ }^{21}$. La razón es muy simple: Tánger tenía el mismo estatuto jurídico que las colonias norteamericanas, es decir, el de plantación. El matiz es importante porque las Actas de Navegación de 1660 y 1663 prohibían la exportación de una serie de mercancías de las colonias norteamericanas, salvo en caso de que se llevaran a puertos ingleses, y prohibían también la im-

19 British Library (BL), Add. 36.785. Los porcentajes se refieren exclusivamente al puerto de Londres que, no obstante, concentraba la mayor parte del comercio exterior inglés. En un documento fechado en torno a 1660 , se había llegado a plantear que la entrega a Inglaterra de las posesiones portuguesas en el norte de África - lo como finalmente sucedió, aunque sólo en el caso de Tánger- permitiría que las mercancías procedentes de la zona — se citan expresamente el «trigo, arroz, vino, aceite, pasas, higos, dátiles, almendras, azúcar, cera, plumajes, caballos, pieles, ganados, estaño y oro"- pudieran sustituir a las que se traían de España y proporcionaría ingresos suficientes a la hacienda pública inglesa como para financiar la conquista de Berbería «y unir aquellos territorios a la corona de V. Mag.» De esta forma, el rey de Inglaterra pasaría de mero "Defensor de la Fe» a «Defensor de la Cristiandad» porque de lo que se trataba, en última instancia, era de extender las conquistas que se llevaran a cabo en el norte de África hasta la misma Jerusalén (Real Academia de la Historia, manuscritos, $\mathrm{K}-12$, fols.. 471-482).

20 Según una carta enviada en julio de 1664 por el cónsul inglés en Cádiz, Martin Wescombe, al Duque de Medina Sidonia a raíz de que se prohibieran los intercambios entre España y el norte de África, desde Tánger se enviaba «en diferentes ocasiones» a Gibraltar, Vejer, Tarifa, Chiclana y Conil, un barco longo llamado «Isabella» «así como otros barcos de dicho precidio», todos ingleses, a buscar «refrescos de legumbres, frutas y otras cosas» (BL, Solane, 3513, fol. 8). El octubre de ese año, España permitió que se hiciera una excepción con Tánger aunque «de manera que sólo se balga aquella plaza de lo que hubiere menester sin dar motivo a justa queja que desde ella pase a Portugal ningún género " (PRO, State Papers, Spain, 94/47, fol. 80). Estos intercambios reportaban a los españoles unos 100.000 reales de a ocho al año en 1674 (DE LA VeronNE, 1972, pág. 86).

${ }^{21}$ Según el autor anónimo de la descripción de Tánger en 1674, «para todos quantos navios vienen de todos nuestros dominios en las Indias [occidentales] hacia Levante, es también escala Tánger y les sirve de abrigo y descansadero; ya venga de Terranova y Nova Escocia con bacallao, y pasen a España, Italia, Turquía y todo el Mediterráneo; ya vengan de Virginia con tabacos; ya de Nova Anglia con castores, açúcares, corambre; ya de Jamaica con cacao, açúcar y otros géneros; ya de Barbadas, las Bermudas, Insula Longa, el Nuevo Yorque y otras muchísimas partes adonde tenemos trato y contrato, o posesiones en las Indias Occidentales» (DE LA VERONNE, 1972, págs. 121-122). 
portación de mercancías directamente desde Europa, salvo que procedieran de puertos ingleses. Los intercambios entre las plantaciones, sin embargo, no estaban prohibidos, por lo que, al menos en teoría, las relaciones mercantiles entre las colonias norteamericanas y Tánger podían considerarse legales.

Los gestores de las aduanas inglesas, arrendadas hasta el año 1672, año en que pasaron a ser administradas directamente por el Estado, se oponían a estos intercambios porque reducían sus ingresos. Ello dio lugar a un interesante alegato por parte de quienes defendían la existencia de relaciones comerciales directas entre Tánger y las colonias británicas de América del Norte que merece la pena resumir. ¿Cuáles eran sus argumentos? Básicamente, tres: que el abaratamiento de las mercancías llevadas directamente desde las colonias, esto es, sin pasar por Inglaterra, incrementaría el comercio inglés en el Mediterráneo en detrimento de sus rivales; que los derechos aduaneros que se recaudaran permitirían reducir la carga económica que suponía mantener la guarnición de Tánger; y, finalmente, que dichos intercambios animarían a los mercaderes y factores a instalarse en la plaza lo que, en definitiva, serviría para consolidar e incrementar su población. Esto, a su vez, permitiría que la recluta de los soldados de la guarnición se pudiera llevar a cabo entre sus propios habitantes y sin la necesidad -y el gasto- de llevarlos desde Inglaterra ${ }^{22}$. A pesar de la polémica, lo cierto es que las relaciones comerciales directas entre las colonias británicas de América del Norte y. Tánger debieron poco relevantes.

Junto al pequeño tonelaje de la mayor parte de los barcos entrados en el puerto de Tánger, confirma también cuanto llevamos diciendo acerca del corto radio de la mayor parte de las operaciones mercantiles que se llevaban a cabo en la ciudad el testimonio siguiente. Con motivo de los intereses de demora exigidos en el pago de una letras por el mercader inglés Samuel Luke, relacionadas con la redención de algunos cautivos españoles que se encontraban en Argel, los también mercaderes tangerinos Guillermo Staines, Valdevino Gascoine, Duarte Rothe, Juan Wollaston, A. Marín, Jenquin Thomas y Guillermo Carpenter, declararon que el citado Samuel Luke «y otros hombres de negocios, han avançado sobre mercaderías de Inglaterra veynte y cinco por ciento en el término de tres meses y en algunas ocasiones han tenido la misma ganancia dos o tres veces en el término de un año, y por los cinco años postreros no ha pasado un año, en el qual no hemos ganado, o sabido que un mercader $u$ otro ha tenido poco mas o menos la misma ventaja, y en algunas ocasiones más» ${ }^{23}$. Estas afirmaciones interesan porque confirman la tesis de que Tánger no llegó a ser jamás un puerto de rango mundial. En efecto, si los intercambios entre Tánger y las colonias británicas de América del Norte hubieran tenido relevancia, la duración habitual de las operaciones mercantiles que se llevaban

22 Reasons for the permitting of the English plantations in America to bee brought directly to Tanger before landed in England (sin fecha pero, seguramente, anterior al año 1672) (BL, Eg. 2.395, fols. 652-660).

23 BL, Sloane, 3513, fol. 120. 
a cabo en la ciudad no habría sido de tres meses, como señalaban los testigos que Samuel Luke presentó en defensa de sus intereses, sino de más de un año.

En otro orden de cosas, hay que añadir que Tánger era un enclave aislado en medio de un territorio hostil, por lo que las preocupaciones defensivas dieron lugar a la existencia de un entramado institucional en el que la posición predominante correspondió en todo momento a los gobernadores militares ${ }^{24}$. El enfrentamiento entre éstos y el poder civil constituyó un rasgo característico de la historia del Tánger inglés y fue considerado por los contemporáneos uno de los factores determinantes del rechazo de muchos mercaderes a instalarse de forma permanente en la plaza ${ }^{25}$. Este enfrentamiento llegó a su punto culminante durante el mandato del gobernador Henry Norwood. En efecto, Norwood acusó a John Bland, primer alcalde de Tánger, de prácticas comerciales monopolísticas. Éste, por su parte, responsabilizó al primero de corrupción. Temiendo por su vida, Bland tuvo de abandonar la ciudad en $1669^{26}$.

El mantenimiento de Tánger costaba a las arcas de Inglaterra unas 60.000 libras al año, suma que se tenía que remitir en su totalidad desde el exterior, habitualmente vía Cádiz, ya que la ciudad no producía ingresos suficientes para costear los gastos de la guarnición. La cuestión es importante porque cuando la Corona inglesa intentó que el Parlamento contribuyera al mantenimiento de Tánger se encontró ante una oposición frontal, básicamente por motivos políti$\cos ^{27}$. En efecto, el Parlamento inglés siempre vio con recelo la existencia de la guarnición de Tánger, cuyas tropas, integradas mayoritariamente por católicos irlandeses, podían ser utilizadas por el rey para imponer su voluntad a los representantes del país ${ }^{28}$. El tema de la financiación de Tánger terminó vinculándose a la intención del Parlamento de que Carlos II excluyera a su hermano, el futuro Jacobo II, católico, de la sucesión. La negativa del rey significó que el abandono de Tánger se convirtiera en una mera cuestión de tiempo, dada la imposibilidad de que los ingresos de la Corona pudieran financiar por sí solos los gastos de la guarnición. La decisión de abandonar la plaza se tomaría a comienzos del año 1683 , ejecutándose un año después ${ }^{29}$.

24 El establecimiento de un poder civil en Tánger tuvo lugar en virtud de un «royal charter» de 4 de junio de 1668 (Routh, 1912, pág. 117).

${ }_{25}$ The present interest of Tangier, 1679, pág. 2.

26 Bland no sólo era el alcalde de la ciudad sino también el mercader más rico de Tánger (WILLIAMS, N., «The Tribulations of John Bland, Merchant. London, Seville, Jamestown, Tangier, 16431680", en The Virginia Magazine of History and Biography, vol. 72, january 1964, págs. 19-41).

27 La solicitud de ayuda para el mantenimiento de la guarnición de Tánger se puede ver en $T$ he House of Lords Journal, vol. 13, pág. 716 (día 15-12-1680).

28 A partir de su incorporación a la Corona inglesa los habitantes de Tánger disfrutaron de libertad religiosa, circunstancia que permitió la existencia de una importante :comunidad mercantil judía de origen tanto europeo como norteafricano así como la práctica del catolicismo.

29 La misión fue encomendada al almirante George Legge, primer barón de Dartmouth, cuyo equívoco comportamiento durante la huida de Jacobo II de Inglaterra, años después, le llevaría a la Torre de Londres, donde murió en 1691. 
Lo expuesto hasta aquí no significa que Tánger careciera de la más mínima relevancia para Inglaterra entre 1661 y 1684. Tánger permitió mantener abiertas las relaciones comerciales con España durante la segunda mitad del año 1665 y primeros meses de 1666 en que Londres sufrió una de las peores epidemias de peste de su historia y sirvió de refugio a.las flotas procedentes de Terranova y Esmirna durante la primera y segunda guerras anglo-holandesas ${ }^{30}$. Tánger, así mismo, jugó un importante papel en la lucha contra la piratería en el norte de África. En efecto, aunque la Navy redujo de manera notable sus efectivos entre la finalización de la tercera guerra anglo-holandesa en 1674 y el comienzo de la guerra de la Liga de Augsburgo contra Francia en 1689, el Almirantazgo otorgó en estos años una prioridad absoluta a los asuntos mediterráneos. La presencia permanente de un escuadrón de la Navy en la zona hizo más costosa la piratería en el Mediterráneo occidental, de ahí que las regencias del norte de África se avinieran a firmar acuerdos de paz con Inglaterra y que los barcos ingleses ganaran posiciones en el comercio intramediterráneo ${ }^{31}$.

A pesar de ello, sin embargo, la posesión de Tánger no supuso un cambio sustancial en la posición mercantil y militar de Inglaterra en el Mediterráneo en el último tercio del siglo XVII. Esto es en definitiva lo que explica la decisión de abandonar la ciudad.

A partir del año 1684 Inglaterra careció de una base propia en el Estrecho, razón por la cual presionó a España, su aliada desde los tratados de paz y de comercio de 1667 y 1670, para que se concediera a los barcos de la Navy la posibilidad de disponer de almacenes permanentes en Gibraltar ${ }^{32}$. La cuestión fue sometida a consulta en el Consejo de Guerra, informándola entre otros el conde de Aguilar, general de las costas de Andalucía. Su opinión, como la de todos los miembros del Consejo de Guerra, fue radicalmente contraria a la petición presentada por Inglaterra «por ser [Gibraltar] la plaza mas envidiada de Europa y que sin gran dificultad se podría hazer inexpugnable». A pesar de ello, en diciembre de 1685 se dieron instrucciones al gobernador de la plaza gibraltareña para que se concedieran los almacenes solicitados. De forma inmediata, el primero de los barcos enviados al efecto —el «Mercader de Venecia»- procedió a desembarcar los pertrechos y municiones que transportaba ${ }^{33}$.

30 A discourse touching Tangier, 1680, págs. 4-9.

31 HORNSTEIN, S.R.: The Restoration Navy and the English Foreign Trade, 1674-1688. A Study in the Peacetime Use of Sea Power, Aldershot, 1991, págs. 8 y 207.

32 Conviene tener presente que desde la firma de los tratados de paz y de comercio de 1667 y 1670 , los barcos ingleses carenaban y obtenían los suministros que necesitaban para mantenerse operativos en los puertos del sur de España, no en Tánger, debido à la falta de instalaciones adecuadas para ello en el puerto norteafricano. Como ejemplo se puede mencionar la carta dirigida al virrey de Valencia el 20 de mayo de 1681 para que se diera acogida en Alicante a la escuadra de bajeles británicos que habían carenado en Gibraltar y se dirigían para ponerse a vista de Argel (PRO, State Papers, Spain, 94/65, fol. 304).

33 Archivo General de Simancas, Estado, leg. 3961. 
La solicitud de arrendar dentro de los muros de Gibraltar diversas «casas y lonjas donde poder ençerrar todo género de provisiones, municiones y pertrechos necesarios para entretener» los barcos de la Navy, realizada por el embajador inglés al rey de España en febrero de 1686 fue, sin embargo, denegada ${ }^{34}$.

\section{MÁS ALLÁ DE LA REIVINDICACIÓN TERRITORIAL Y DE LA DEFENSA IMPERIAL: EN TORNO A LA FUNCIONALIDAD ECONÓMICA DE GIBRALTAR EN EL SIGLO XVIII}

La conquista de Gibraltar no fue un azar histórico. Los ingleses ya habían estado o querido estar allí mucho antes del año 1704; de hecho, los primeros planes conocidos para tomar la ciudad datan del año $1625^{35}$. Con posterioridad a esta fecha, en 1656, una flota enviada por Cromwell, tras fracasar ante Cádiz y bombardear Málaga, trató de apoderarse de la roca, pero la operación se frustró por la pérdida del «Cullen», un navío auxiliar que transportaba material de apoyo para el asalto ${ }^{36}$. Durante el reinado de Carlos II de Inglaterra, periodo en el que las relaciones con España mejoraron de forma significativa y en el cual se firmaron los tratados de paz y de comercio de 1667 y 1670 como ya hemos indicado, los barcos de la Navy carenaron frecuentemente en Gibraltar, una vez abandonada Tánger. Y a partir de 1702, por fin, iniciada ya la guerra de Sucesión, todos y cada uno de los almirantes a los que se encargaron misiones en el estrecho recibieron instrucciones para capturar Gibraltar, lo que finalmente ocurrió en los primeros días de agosto de $1704^{37}$.

La noticia de la toma de Gibraltar fue acogida por ciertos sectores de la opinión pública inglesa con «spight and detraction», esto es, de forma malévola y con ánimo de restar importancia a la operación ${ }^{38}$. Las discrepancias en torno a la valoración que merecía Gibraltar continuaron una vez terminada la guerra, aunque planteándose ahora en un terreno distinto, mucho más delicado. ¿Podían ser compatibles el mantenimiento de un ejército permanente como el que se necesitaba para defender Gibraltar y el régimen de libertades del que disfrutaban el Parlamento y el pueblo de Inglaterra desde la Gloriosa Revolución del año 1688 ?39. La cuestión, que ya se había planteado en 1697, esto es, al finalizar la

34 Pro, State Papers, Spain, 94/72, fol. 37.

35 De LuNA, J.C.: Historia de Gibraltar, Madrid, 1944, pág. 283. Fueron presentados por el coronel Henry Bruce al Príncipe de Gales recién llegado éste de su viaje a Madrid.

36 CAPP, B.: Cromwell's Navy. The Fleet and the English Revolution, 1648-1660, Oxford, 1989, pág. 87.

37 CORBETT, W.: England in the Mediterranean, 1603-1713, London, 1904, vol. II, pág: 255.

38 Uno de los objetivos del autor.o autores de $A$ Narrative of Sir George Rooke's late Voyage to the Mediterranean, folleto fechado en septiembre de 1704, esto es, apenas un mes después de la conquista de Gibraltar, era precisamente el de mostrar la utilidad e importancia de la misma frente a lo que estaba dando a entender «a certain faction» (pág. 1).

39 El peligro radicaba en que la Corona utilizara en su favor, frente a las prerrogativas del Parlamento, una fuerza tan poderosa. Encontramos este razonamiento en Concordia Discors: or, An Ar- 
guerra de la Liga de Augsburgo, surgió de nuevo al término de la guerra de Sucesión y con más fuerza si cabe puesto que Gibraltar se encontraba a pocos días de navegación de Londres ${ }^{40}$. Ahora, sin embargo, y a diferencia de lo que había sucedido años atrás con respecto a Tánger, la Corona y el Parlamento trabajaron juntos por el mantenimiento de Gibraltar bajo la soberanía británica, y ello a pesar de las promesas circunstanciales realizadas por el rey Jorge I sobre la devolución de la roca a España ${ }^{41}$.

¿Respondió la conquista de Gibraltar a las expectativas creadas por sus ocupantes?; o, en otras palabras, ¿se convirtió en la base naval y en el emporio comercial que ambicionaba Inglaterra? La cuestión es difícil de responder porque habría que establecer una clara distinción entre la funcionalidad militar de la plaza y la mercantil y, también, porque en este último ámbito, el mercantil, el único del que nos ocuparemos en este trabajo, la situación de Gibraltar cambió extraordinariamente con el paso de los años ${ }^{42}$.

John Sinclair, reputado financiero y economista escocés, consideraba a finales del siglo XVIII que la importancia que se atribuía a Gibraltar desde un punto de vista comercial era totalmente desproporcionada, por lo que se debía devolver a España a cambio de algún tipo de compensación ${ }^{43}$. Hasta qué punto era correcta esta apreciación y si las cosas habían sido así desde el principio de la presencia inglesa en la roca no lo sabemos con certeza porque la falta de in-

gument to prove that the posesion of Dunkirk, Port Mabon, Gibraltar, and other places by the English may be of worse consequence to these Nations than if they bad still continued in the hands of the French and Spaniards, 1712 , donde se habla de la necesidad de disponer de 10.000 soldados para la defensa de Dunquerque, de otros 15.000 para la de Gibraltar y Menorca y de otros 23.000 más como «standing army» (ejército permanente).

40 En 1714, Torys y Whigs mantenían posiciones opuestas con respecto a la existencia o no de ese ejército permanente, siendo los primeros contrarios a la misma. Véase J. HoppiT: $A$ Land of Liberty? England 1689-1727, Oxford, 2000, pág. 285.

41 Holland Rose, J. «Sea Power and Expansion, 1660-1763", en The Cambridge History of the British Empire, vol. I, Cambridge, 1959, pág. 509. Véase The Humble Address of ... the Lords ... and Commons in Parliament assembled \{advocating the retention of Gibraltar and Minorca\}, presented to bis Majesty on ... the twenty-fifth day of March, 1729. With bis Majesty's most gracious Answer, London, 1729. Sobre las negociaciones en torno a Gibraltar versan los estudios de CONN, S.: Gibraltar in British Diplomacy in the Eighteenth Century (New Haven, 1942) y GómEz MOLLEDA, D.: Gibraltar: una contienda diplomática en el reinado de Felipe V (Madrid, 1953). Los primeros años del contencioso se pueden seguir en DE BÉThencourt MASsiEu, A.: Relaciones de España bajo Felipe V, Alicante, $1998,2^{\mathrm{a}}$ ed.

42 Desde un punto de vista militar, Gibraltar respondió plenamente a las expectativas que había creado en los responsables de la Navy. Los sitios a los que fue sometida la roca a lo largo del siglo XVIII pondrían de manifiesto su condición de enclave prácticamente inexpugnable.

43 SINCLAIR, J.: The propriety of retaining Gibraltar impartially considered, London, 1783, págs. 12 y 32. Esta posición se inscribe dentro de las negociaciones de paz que siguieron a la Guerra de independencia de los Estados Unidos y durante las cuales el gobierno británico llegó a dar su aprobación al intercambio de Gibraltar por Puerto Rico.

Hispania, LXV/3, núm. 221 (2005) 1043-1062 
formación seriada acerca del tráfico naval y mercantil de Gibraltar hasta comienzos del siglo XIX lo hacen imposible 44 .

No obstante, algunos trabajos publicados poco después del Tratado de Utrecht, como el firmado bajo el seudónimo de «A Turkey Merchant» en $1720^{45}$ o el escrito «by a gentleman of the Navy» en $1725^{46}$, ponen claramente de manifiesto que Gibraltar distaba de ser por entonces un enclave comercial de importancia ${ }^{47} ; \mathrm{y}$ ello a pesar de su declaración de puerto franco el año $1706^{48}$.

Según el primero de los trabajos citados, la diferencia entre las posibilidades que ofrecía Gibraltar y la realidad de lo conseguido desde el año 1704 era poco menos que escandalosa. En efecto, Gibraltar podía jugar un papel fundamental en la defensa del comercio británico en el Mediterráneo ${ }^{49}$, «destruir» el de Francia con Cádiz y las Indias Occidentales y prevenir el encuentro de las flotas francesas del Atlántico (Brest) y del Mediterráneo (Tolón). Por otra parte, en caso de ruptura con España, las colonias de mercaderes británicos de Cádiz o Málaga podrían refugiarse en Gibraltar, desde donde continuarían llevando «a private trade to Spain very much to our own advantage»50. Finalmente, con respecto a Berbería, consideraba el autor del folleto que la única forma que tenía Inglaterra de hacerse respetar por las regencias del norte de África era

44 SÁNChez MANTERo, R.: Estudios sobre Gibraltar. Política, diplomacia y contrabando en el siglo XIX, Cádiz, 1989, reproduce el valor de las exportaciones de los Estados Unidos y Gran Bretaña a Gibraltar a partir de 1814 y 1815 , respectivamente. No disponemos de nada similar para el periodo anterior de la presencia británica en la roca.

45 $A$ letter to the Lords Commissioners for the Trade and Plantations, concerning the advantage of Gibraltar to the trade of Great Britain. With some proposals to render that place more useful. By a Turkey merchant, 1720 .

46 Gibraltar, a bulwark of Great Britain in a letter to a member of Parliament: containing some considerations on the importance of the place, in respect to our trade in general; but particularly with regard to Barbary, Spain, France, etc. By a gentleman of the Navy, 1725.

47 La información disponible sobre la economía marítima de Gibraltar en la década de 1720 es, sin embargo, contradictoria. Según el diario de Edward Burd, supercargo del «Christian», que había llegado para descargar vino, durante el mes en que estuvo en Gibraltar —esto es, de mediados de febrero a mediados de marzo de 1727- el número de barcos mercantes que salieron de Gibraltar superó los cien (HANNAY, R.K. "Gibraltar in 1727", en Scottish Historical Review, 16, 1918-19, págs. 325-334. El dato, en la pág. 334).

48 Calendar of Treasury Papers, vol. III (1702-1707), día 7-2-170 $5 / 6$ (London, 1874).

49 En junio de 1693, un grupo de barcos mercantes ingleses que volvían de Turquía fue atacado por la flota francesa cerca de Gibraltar, estimándose las pérdidas en cerca de un millón de libras (PRO, State Papers, Spain, 94/210, fol. 196). Según D. Defoe, cuando G. Rooke tomó Gibraltar en 1704 "was moved to it by the consideration that such a misfortune [la destrucción de la flota de Turquía en 16931 as had formerly be fallen him and the trade of the nation, would be for ever prevented" (1720, pág. 6).

50 Esta previsión se confirmaría plenamente en los años siguientes, como se deduce de la orden de 3-11-1739 para que se impida la introducción de ropas inglesas de los almacenes establecidos en Faro y Gibraltar por mercaderes ingleses que antes vivían en Cádiz (MATILLA TASCón, A.: Catálogo de la Colección de Órdenes Generales de Rentas, Madrid, tomo I, $\mathrm{n}^{\circ}$ 650). 
disponer de una fuerza militar permanente en la zona «both to distress their trade, as well as preserve our own. And where can we have a power more aptly placed for these purposes, than at Gibraltar?»\$1. Si la posesión de Gibraltar, según el citado «Turkey merchant», tenía tantas ventajas, ¿por qué había que de tomar medidas a fin de «to give new life and vigour to the languishing commerce of Gibraltar»? 52 .

En principio, podemos descartar que la debilidad del comercio gibraltareño en estos años se debiera principalmente a las acciones emprendidas por España para bloquear la roca ya que, incluso durante la guerra de Sucesión, los intentos de impedir el comercio con Gibraltar levantaron tales protestas entre los mercaderes de los puertos andaluces que las autoridades se vieron obligadas a rectificar de inmediato las medidas dictadas en ese sentido ${ }^{53}$.

Los textos de la época apuntan en realidad hacia otro tipo de problemas. Para empezar, la falta de una moneda sana. En efecto, la mayor parte de la moneda que circulaba en Gibraltar hacia 1720 ó 1725 se había acuñado en Barcelona durante la guerra de Sucesión. Era, pues, una moneda con un contenido de plata inferior en un diez por ciento al real de a ocho acuñado en otras cecas de la Península y que, además, había sufrido desde entonces continuos recortes ${ }^{54}$. ¿Cómo abordar este asunto? Conocedor seguramente de la reforma monetaria que se había llevado a cabo en Inglaterra en 1696 con objeto de hacer frente a problemas similares, "the Turkey merchant» reclamaba la sustitución de la moneda en circulación por "good Spanish money», corriendo el gobierno inglés con los gastos y pérdidas derivados de la operación ${ }^{55}$.

La presencia de cónsules extranjeros en la roca - francés, holandés y genovés- se consideraba también un obstáculo para el desarrollo mercantil de Gibraltar porque los derechos de consulado que percibían encarecían las transacciones $^{56}$. Con todo, el principal inconveniente para el afianzamiento de Gibraltar

51 A letter to the Lords Commissioners, pág. 7. Las referencias a Berbería aparecen en otros muchos textos de la época como, por ejemplo, Reasons why we ought not on any account, to part with Gibraltar (Real Academia de la Historia, 2/1746-1, sin fecha).

52 Gibraltar, a bulwark, pág. 40.

53 Veáse, por ejemplo, Señor. Los comerciantes de la ciudad de Málaga, a quienes (...) se les fulminó causa de ilícito comercio con Gibraltar, por el año pasado de 1712 (Real Academia de la Historia, $11 / 9377, \mathrm{n}^{\circ} 128$ ). Sobre las relaciones comerciales entre Cataluña y Gibraltar durante la guerra de Sucesión consúltese VILAR, P.: Le "Manual de la Compañya Nova» de Gibraltar: 1709-1723, Paris, 1962. Véase también el artículo de GARCía FERNÁNDEZ, N., «El comercio de Cádiz con Inglaterra durante la Guerra de Sucesión", en Economía marítima: actas de los XIII Encuentros de Historia y Arqueologia, San Fernando, 1998, págs. 155-166. Sobre el corso español en la zona OCAN̄A TORRES, M. (1993): El corso marítimo español en el Estrecho de Gibraltar (1700-1802), Algeciras.

54 JONES, D.W.: War and Economy in the Age of William III and Marlborough, Oxford, 1988, págs. 87-88.

ss $A$ letter to the Lords Commissioners, pág. 13.

56 Además se pensaba, no sin razón, que se trataba de espías más que de otra cosa. Según el censo llevado a cabo en agosto de 1725 Gibraltar contaba por entonces con 55 vecinos de nacionalidad britá- 
como enclave mercantil, según los autores citados, era la ausencia de un poder civil y de unos tribunales de justicia donde los mercaderes pudieran acudir para resolver sus diferencias y conflictos ${ }^{57}$. Como reconocía el autor del segundo de los textos que estamos comentando, «trade (...) cannot flourish under a military power» ${ }^{98}$.

Las críticas a las arbitrariedades de los gobernadores militares de la plaza gibraltareña, como había ocurrido en Tánger medio siglo antes, fueron permanentes a lo largo de la primera mitad del siglo XVIII. Estas arbitrariedades se describen con todo detalle en un libro cuyo título ha sido motivo de equívoco 59. Y esto porque el autor no proponía el abandono de Gibraltar sino reformar su administración y, especialmente, acabar con la corrupción de los gobernadores militares, quienes obtenían importantes ingresos mediante la manipulación del tipo de cambio de las transferencias de dinero para el pago de la guarnición y mediante el control del aprovisionamiento de las tropas, confiado en régimen de monopolio a una sola compañía ${ }^{60}$. No tiene nada de extraño, pues, que ante la continuidad en el tiempo de una administración tan deficiente, algunos se preguntaran si ello no respondía, en realidad, a que las autoridades británicas carecían de ideas claras acerca del futuro de la roca ${ }^{61}$.

En realidad, ideas y proyectos no faltaron ${ }^{62}$. Uno de los primeros programas globales acerca de lo que se debía hacer en Gibraltar lo encontramos en el texto de Henry Maxwell, publicado en 1.723, y titulado «An essay on Minorca, and Gibraltar». Sabedor de que uno de los principales problemas que planteaba la posesión de Gibraltar era el de la financiación de las tropas encargadas de su defensa, Maxwell propuso que el gobierno británico promoviera el asentamiento en la roca de 1.800 familias judías, cada una de las cuales pagaría 20 libras al año (24 en tiempo de guerra). Las 36.000 libras anuales procedentes de este impuesto servirían para vestir, armar y pagar los salarios de 692 marineros; los necesarios para mantener operativos dos barcos de 50 cañones cada

nica de edades comprendidas entre los 16 y los 60 años frente a 190 genoveses, 14 franceses, 7 holandeses y 111 judíos. HiLls, G.: Rock of contention. A bistory of Gibraltar, London, 1974, pág. 234.

57 «The greatest misfortune to this place is the want of a well-constitued civil power» ( $A$ letter to the Lords Commissioners, pág. 11).

58 Gibraltar, a bulwark, pág. 40. El establecimiento de un poder civil en Gibraltar se llevó a cabo finalmente en 1740 (The Royal Charter for establishing a civil Government at. Gibraltar to which is prefixed a prefatory discourse recapitulating the benefits which have been proposed therefrom, London, 1742).

59 Reasons for giving up Gibraltar, London, 1749.

60 Reasons, págs. 28-29.

$61 \mathrm{Al}$ respecto de Three letters relating to the navy, Gibraltar, and Port Mabon, publicadas en 1757 pero referidas a los años 1747-1748, señalaba Sinclair en The propriety, que «the author well remarks that the Ministers of this country never acted as if they intended to keep possession of Gibraltar, but as if they only waited for a proper opportunity to deliver it up» (pág. 42).

${ }_{62}$ Una de las propuestas más sorprendentes fue la de J. Davies, quien en 1731 propuso que los delincuentes deportados de Inglaterra cumplieran sus condenas en Gibraltar como galeotes (DAVIES, J.: An bumble proposal for the increase of our bome trade, and a defence to Gibraltar, London, 1731). 
uno y dos galeras ${ }^{63}$. También se crearía un banco («Lumbard»), sufragado inicialmente con fondos públicos y con capacidad para emitir moneda papel y negociar letras de cambio, donde los gibraltareños podrían tomar prestadas las sumas que necesitaran para financiar sus actividades, pagando unos intereses de tan sólo el tres por ciento. A juicio de Maxwell, la existencia de este banco era del todo punto necesaria para garantizar la supervivencia de los «poor manufacturers» que habían venido a poblar la roca tras su conquista por Inglaterra. Por lo que se refiere finalmente a las funciones comerciales que podría desempeñar Gibraltar, Maxwell consideraba en que si se autorizaba el comercio directo entre las Indias Occidentales y Gibraltar, el azúcar y el tabaco portugueses serían desplazados de los mercados mediterráneos por los de procedencia británica. Merece la pena que nos extendamos en este punto.

A comienzos de la década de 1720 Gibraltar era ya una importante plataforma para el comercio entre Terranova (pescado), el Estrecho e Inglaterra ${ }^{64}$. Cuestión distinta es la de los intercambios directos entre las colonias británicas de América del norte y Gibraltar, prohibida por las Actas de Navegación, pero que contaba con muchos partidarios. Uno de ellos, como acabamos de ver, era Henry Maxwell. Otro, también por entonces, argumentaba que si se permitía el envío de azúcar, tabaco - tanto el llamado «scrub», de mala calidad, como el tabaco común - y otras producciones de las colonias se obtendrían unas ganancias «de muchos millares de libras al año» que, entre otras cosas, podrían servir para financiar el déficit comercial de Gran Bretaña con Turquía ${ }^{65}$.

La prohibición mencionada no parece que lograra impedir el contrabando de tabaco a través de Gibraltar, cuestión ésta que habría que tener en cuenta a la hora de explicar que el gobierno español optara por reformar la gestión de la renta, aplicando el sistema de administración directa, a partir del año $1731^{66}$.

63 Hacia 1720, el mantenimiento de Gibraltar costaba unas 50-60.000 libras anuales, cifra no muy alejada de las 36.000 que pretendía recaudar Maxwell de la población judía. Esta cifra pasó a ser de 100-120.000 libras a mediados de siglo y de 350.000 durante el sitio que vivió la roca a comienzos de la década de 1780 . Tomo estos datos de $A$ Letter to the Independent Whig, pág. 11; Reasons for giving up Gibraltar, pág. 54 y The propriety, págs. 20-21. Compárese el importe de los gastos que suponía el mantenimiento de Gibraltar con las 5.000 libras anuales que se recaudaban en la plaza por todos los conceptos a mediados del siglo XVIII (las rentas de algunas casas y los impuestos que pagaban los vinos y licores que se consumían en la roca) (PRO, T 1/363/43).

64 GEE, J.: Consideraciones sobre el comercio y la navegación de Gran Bretaña, Madrid, 1753 (la primera edición del original inglés de este libro se publicó en 1729). Según Gee, «se hace presentemente algún comercio entre Inglaterra, Terranova y el Estrecho de Gibraltar: muchas de nuestras fragatas van a Terranova a cargar de pescado, que venden en Gibraltar, en donde toman mercaderías para la Inglaterra, la Holanda y el Báltico» (págs. 85-86).

65 GeE, Consideraciones, págs. 87-88 y 90.

66 RodríGuez GoRDillo, J.M. «El abastecimiento de tabacos en el marco del estanco español en el siglo XVIII: reflexiones previas para su estudio», en GONZÁLEZ ENCISO, A. y R. TORRES SÁNCHEZ (editores): Tabaco y economía en el siglo XVIII, Pamplona, 1999, págs. 239-270. Según González Enciso, en 1732 fueron aprehendidas en Almería casi 27.000 libras de tabaco de contrabando 
Entre otras razones, al menos por lo que hace a Andalucía, donde el consumo y la recaudación eran mayores, porque los posibles arrendatarios de la renta no estaban dispuestos a pagar sumas más altas debido al contrabando que se llevaba a cabo desde la roca ${ }^{67}$.

El tabaco que llegaba a Gibraltar procedía bien de Brasil bien de las colonias británicas de América del Norte, fundamentalmente de Virginia. Sobre el primero sabemos que una parte significativa del mismo, tras pasar por Lisboa, era supuestamente remitida a Nápoles por mercaderes genoveses y napolitanos, aunque lo cierto es que solía terminar en Gibraltar ${ }^{68}$, donde existía una importante colonia genovesa cuyo número pasó de 190 a 597 individuos entre 1725 y $1753^{69}$.

La comercialización y distribución del tabaco de Virginia - que, como comentaba un comerciante español a finales del siglo XVIII, siempre abundaba en Gibraltar ${ }^{70}$ - difería completamente de la del tabaco brasileño. En efecto, el tabaco constituía, como ya hemos señalado, una de esas mercancías «enumeradas», en la terminología inglesa de la época, que no se podían exportar directamente más que a la metrópoli, por lo que el contrabando de tabaco a través de Gibraltar no implicaba tan sólo un fraude para la hacienda pública española sino también para la británica ${ }^{71}$.

Quienes controlaban el comercio de tabaco de Virginia, en origen, eran los colonos de América del Norte, no los mercaderes de la metrópoli, por lo que

procedentes de Gibraltar («En torno al contrabando de tabaco», en Estudios de Historia Moderna y Contemporánea, 1991, pág. 207).

67 Gibraltar, a bulwark, pág. 28.

68 TORRES SÁNCHEZ, R. «El Banco de San Carlos y el negocio del tabaco. Una investigación de mercado en el siglo XVIII», en S. De LUXÁN MELÉndeZ, S. SOlbeS FerRI y J.J. LAFORET, eds.: El mercado del tabaco en España durante el siglo XVIII, Las Palmas de G.C., 2000, págs. 105-150. Véase la pág. 122 , nota 19 .

69 HILls; G.: Rock of contention, pág. 288. Compárense estos datos con el número de súbditos británicos - 57 y 331 en 1725 y 1755 - o con el tamaño de las colonias judías, española y portuguesa en el último de los dos años citados: 575,185 y 25 individuos, respectivamente (pág. 288). Estas cifras no incluyen la guarnición militar. Según las autoridades de la roca, el contrabando de tabaco - ibrasileño? - era una actividad controlada por mercaderes genoveses y extranjeros por lo que «the English merchants entirely disclaim it; and some of the principals of them (...) think some restrictions in this respect absolutely necessary» (Lieut. Gen. Fowke, 6-2-1756, PRO, T 1/369/5).

70 TORRES SÁNCHEZ, R. (1999); "Capitalismo internacional y política estatal. Los asientos de tabaco en España durante la segunda mitad del siglo XVIII", en GoNZÁlEZ ENCISO, A. y R. ToRRES SÁNCHEZ: Tabaco y Economía en el siglo XVIII, págs. 415-456. La cita en la pág. 424.

71 Las Actas de Navegación de 1660 y 1663 prohibieron la exportación de una serie de mercancías de las colonias norteamericanas - a las que se incorporó el arroz en 1705-, salvo en el caso de que se llevaran a puertos ingleses. Igualmente, prohibieron la importación de mercancías procedentes de Europa, excepto si habían pasado previamente por Inglaterra. Analizamos uno de los capítulos más importantes de las exportaciones legales de las colonias británicas de América del Norte a España en J.I. MARTíNEZ RUIZ, «El mercado internacional de cereales y harina y el abastecimiento de la periferia española en la segunda mitad del siglo XVIII: Cádiz, entre la regulación y el mercado", Investigaciones de Historia Económica, 1 (2005), págs. 45-79.

Hispania, LXV/3, núm. 221 (2005) 1043-1062 
estos intercambios crearon una gran preocupación en Londres, sobre todo, a medida que se deterioraban las relaciones con las colonias. Según los responsables de las aduanas de Nueva York, el envío de mercancías enumeradas directamente a Gibraltar se remontaba, como mínimo, a la década de $1740^{72}$. Probablemente, sin embargo, habría que ir más atrás. Como señalaba el autor de "Intereses de Inglaterra mal entendidos en la presente guerra con España», «nosotros [los ingleses] ni aún en tiempo de paz hemos conseguido el embarazar una infinidad de contravenciones a la acta de la navegación» de manera que, como se había visto durante la guerra de Sucesión a la Corona de España, los navíos de Boston o Filadelfia hacían caso omiso de tales prohibiciones y se dirigían directamente al Mediterráneo con mercancías enumeradas a pesar de tratarse de una actividad ilegal73. En 1739, el Parlamento británico permitió las exportaciones de azúcar de Barbados y otras islas de la zona directamente a España, Portugal y el Mediterráneo. Las exportaciones legales de tabaco, por el contrario, siguieron estando monopolizadas por la metrópoli.

En cualquier caso, de la importancia de estos intercambios, que no se limitaban en absoluto ni al tabaco ni a las mercancías procedentes de las colonias británicas, se haría eco por extenso López de Ayala a finales del siglo XVIII, periodo en el que todo parece indicar que Gibraltar se había consolidado ya como un centro mercantil de rango internacional:

\begin{abstract}
«las colonias americanas inglesas, holandesas i dinamarquesas comercian directamente con Gibraltar cargando en él los géneros de su propio consumo, i conduciendo a él para cambiar, vender o dexar en depósito, hasta que se vendan, tabacos, palo de Campeche, bacalao, alquitrán, tablazón, mástiles, rum, arroz, maíz, harina, azúcar, pimienta de Tabasco, jengibre, duelas, algodón, añil i otras mil especies que ofrece el comercio de América, de África, de Asia. Quando pasan al Mediterráneo dexan en Gibraltar los géneros de América, i volviendo con vino, aguardiente, pasas, almendras, naranjas, sedas, limones, sal, etc., cargan géneros de las fábricas de Europa, conducidos allí por los Ingleses, Holandeses, Franceses, vinos de España, i gran número de mulas de berbería para el trabajo de los ingenios de azúcar. La cera i carnes frescas, conducidas del Africa es también artículo cuantioso de este comercio (...). Las costas de Sevilla, Granada, i Cataluña les suministran vinos, ascendiendo un año con otro el que se vende por menor en las tabernas, desde quatro hasta cinco mil pipas (...) sin que entren en cuenta los vinos generosos i de mejor calidad que consume la oficialidad y gente acomodada, ni las grandes partidas que allí se depositan para conducirlas a la América»74.
\end{abstract}

72 Andrew Elliot y Lambt. Morre, responsables de la aduana de Nueva York, a los Lords of Trade, 2-1-1772 (PRO, T 1/492/175).

73 Intereses de Inglaterra mal entendidos en la presente guerra con España, Sevilla, 1741, págs. 79-80. Según el autor, la obra «se concibió al propósito de la guerra pasada» (¿la Guerra de Sucesión?) pero se publicaba ahora con ocasión de la presente.

74 LÓPEZ DE AYALA, I.: Historia de Gibraltar, Madrid, 1782, pág. 375. Aunque publicada en 1782, la obra fue escrita en 1776.

Hispania, LXV/3, núm. 221 (2005) 1043-1062 
A la vista del vuelo que habían alcanzado estos intercambios, apenas sorprende que, consultada la posibilidad de que se autorizara el comercio directo de mercancías prohibidas entre las colonias de América del Norte y el Mediterráneo, los responsables de las aduanas británicas prefirieran inhibirse ante una cuestión tan delicada y que, en sus propias palabras, "podía afectar de forma tan importante a las relaciones de dependencia comercial que mantenían las colonias con la metrópolis ${ }^{75}$. Como es sabido, Londres sólo permitiría el comercio directo de sus colonias norteamericanas -0 de lo que quedaba de ellas, es decir, de Canadá- con Gibraltar a comienzos del siglo XIX ${ }^{76}$.

\section{CONCLUSIONES}

La expansión comercial de Inglaterra — desde 1707 el Reino Unido de Inglaterra y Escocia - se basó en la existencia de una fuerte identificación entre los intereses del Estado y el de los comerciantes y hombres de negocios, de ahí que uno de los principales cometidos de la Navy, tanto en tiempos de paz como de guerra, fuera la defensa de las rutas marítimas que comunicaban Inglaterra con el resto del mundo. Por su peligrosidad, pero también por la importancia que tenían el comercio con Turquía e Italia - por no hablar de los intercambios con España - para la economía británica, el Mediterráneo constituyó una de las áreas de intervención preferente para el Almirantazgo desde mediados del siglo XVII.

A pesar de su cercanía a Inglaterra, la flota del Mediterráneo necesitaba contar en la zona con puertos seguros y, a ser posible, propios, para mantenerse operativa. El apoyo de Inglaterra al proceso de independencia de Portugal permitió que Lisboa cumpliera durante algún tiempo esta función. Lisboa, sin embargo, seguía estando demasiado lejos del Mediterráneo y, sobre todo, planteaba el problema de que el uso de sus instalaciones portuarias dependía de la buena voluntad de las autoridades lusas. Por ello, el matrimonio de Carlos II de Inglaterra con la princesa portuguesa Catalina de Braganza, que aportó como dote la ciudad de Tánger, allanó el camino al deseado objetivo de dispo-

75 PRO, T $1 / 490 / 248$ (6-3-1772).

76 57.Geo III.3.4 (1817). Extensión a Gibraltar de las condiciones establecidas para el comercio directo entre Malta y las colonias y plantaciones británicas $(A$ collection of the statutes now in force, relating to shipping, navigation, commerce, and revenue, in the British colonies and plantations in America and the West Indies from 12 Charles II. To 57 George III. ..., compiled by William Earnshaw, London, 1818, págs. 284-290). El estudio de las estadísticas norteamericanas de comercio permitiría, seguramente, reconstruir el valor de los intercambios con Gibraltar desde finales del siglo XVIII. Esto es lo que sugiere el título del siguiente documento que no hemos podido consultar, pero del que dejamos constancia: Letter and report from the Secretary of the Treasury: accompanying a statement of the value of the exports of the United Status to the ports of Italy, Gibraltar and the Barbary powers, for each of the five years preceding the 30th of September, 1801, Washington, 1802. 
ner de una base propia en el Estrecho. Distintas circunstancias hicieron imposible que Tánger se convirtiera en el eje de los asuntos ingleses en el Mediterráneo, de ahí que terminara siendo dinamitada y abandonada a comienzos del año 1684 .

Esta evacuación, a la que siguió poco después el inicio de un nuevo enfrentamiento con Francia, la llamada Guerra de la Liga de Augsburgo, planteó una vez más, pero ahora con mayor crudeza, la necesidad de disponer en el Mediterráneo no ya de puertos amigos sino de puertos propios que garantizaran la presencia comercial y militar británica en la zona. La oportunidad para lograrlo surgió durante la Guerra de Sucesión y se concretó en la conquista de Gibraltar primero y de Menorca después ${ }^{77}$. Mas allá de la reivindicación territorial y de la defensa imperial, pero sin duda afectada por una y otra, la economía del Gibraltar inglés se adaptó y aprovechó las posibilidades que ofrecía su condición de puerto franco, su situación geográfica entre el Mediterráneo y el Atlántico y su integración en el imperio británico, de manera que a finales de siglo XVIII su condición de enclave comercial de rango internacional era ya un hecho.

77 Menorca no constituye el tema de este artículo por lo que me remito al reciente trabajo de MARTín CORRALES, E. "Mahón en la Edad Moderna: un puerto escasamente aprovechado", en MORAles MOYA, A. coord.: 1802. España entre dos siglos. Ciencia y Economía, Madrid, 2003, págs. 439-455.

Hispania, LXV/3, núm. 221 (2005) 1043-1062 